Check for updates

Cite this: RSC Adv., 2017, 7, 18714

Received 29th December 2016 Accepted 22nd March 2017

DOI: $10.1039 / \mathrm{c} 6 \mathrm{ra} 28800 \mathrm{f}$

rsc.li/rsc-advances

\title{
Organocatalytic synthesis of enantioenriched 1,2,4-triazolines containing a chiral quaternary carbon center
}

\author{
Li-Jun Zhang, Si-Xiang Zhang, Li-Na Fu, Xiao-Yun Li and Qi-Xiang Guo (D)* \\ An efficient asymmetric cyclization reaction of amino-acid-derived isothiocyanates with azodicarboxylates \\ is described. The chiral 1,2,4-triazolines are prepared in good yield (up to $87 \%$ ) and enantioselectivities (up to \\ $95 \%$ ee).
}

Triazoles are one of the most important classes of heterocycles because of their broad biological activities such as antiviral, antiepileptic, anticancer, and anti-HIV activities. ${ }^{1}$ Many triazoles are used in pharmaceuticals, agrochemicals, corrosion inhibitors, photographic materials, dyes, etc. $^{2}$ Therefore, it is important to develop novel methods for the synthesis of structurally diverse triazoles. 1,2,4-Triazolines, one type of important triazole related compounds bearing a potential chiral carbon center at the C-3 position, exhibit good antiviral, anticancer, anti-inflammatory, and anticonvulsant properties. ${ }^{3}$ The racemic synthesis of 1,2,4-triazolines has been reported extensively; ${ }^{4}$ however, the asymmetric synthetic methods are very limited. ${ }^{5}$ In 2010, Jørgensen and co-workers reported preliminary results for the asymmetric synthesis of 1,2,4-triazolines by phase transfer catalysis. ${ }^{5 a}$ Then, Feng, ${ }^{5 b}$ Huang, ${ }^{5 c}$ and $\mathrm{Shi}^{5 d}$ reported the synthesis of chiral 1,2,4-triazolines independently. In these studies, $\alpha$-isocyano esters (I) or azlactones (II) reacted with azadicarboxylates to generate the target chiral triazolines (Scheme 1). In 2013, Shi and co-workers reported an efficient [3 $+2]$ reaction of 3-aminooxindole derived isothiocyanates (III) with azodicarboxylates, producing spirooxindoles in high yields and enantioselectivities. ${ }^{6} \alpha$-Isothiocyanato esters (IV), which can be readily prepared from commercially available amino acids, are useful reactants in the catalytic asymmetric addition reactions with aldehydes, ${ }^{7}$ ketones,${ }^{8}$ or imines, ${ }^{9}$ affording chiral cyclic thiocarbamates in good experimental results. Inspired by Shi's work, ${ }^{6}$ we assumed that the amino acid derived $\alpha$-isothiocyanato esters would be good reactants in the catalytic asymmetric addition to azodicarboxylates. Such a reaction will produce chiral polysubstituted 1,2,4-triazolines bearing a carboxylic functional group at the $\mathrm{C}-3$ position and sulfur

Key Laboratory of Applied Chemistry of Chongqing Municipality, School of Chemistry and Chemical Engineering, Southwest University, Chongqing, 400715, China. E-mail: qxguo@swu.edu.cn

$\dagger$ Electronic supplementary information (ESI) available. CCDC 1043418. For ESI and crystallographic data in CIF or other electronic format see DOI: 10.1039/c6ra28800f substitution at the C-5 carbon (Scheme 1b), and provide an alternative pathway leading to chiral 1,2,4-triazolines. Also, the corresponding products can be converted into structural diversity chiral nitrogen containing heterocycles easily. Herein, we report this chiral tertiary amine catalyzed $[3+2]$ reaction of $\alpha$-isothiocyanato esters with azodicarboxylates, leading to polysubstituted 1,2,4-triazolines in good yields and enantioselectivities.

In the initial study, the phenyl glycine derived isothiocyanato ester 1a was used as reactant to react with di-tert-butyl azodicarboxylate 2a in the promotion of cinchonine 3a. As expected, the desired product $4 \mathbf{a}$ was obtained in a high yield (96\%), albeit with a low enantioselectivity ( $19 \%$ ee). We tried to improve the stereocontrol ability of the catalyst by modifying the 9-OH group of cinchonine and cinchonidine. As shown in Table 1, the modified catalysts $\mathbf{3 b} \mathbf{b}-\mathbf{d}$ gave $\mathbf{4 a}$ in low yields and enantioselectivities (Table 1, entries 2-4). Quinidine $3 \mathbf{e}$ and its derivatives $\mathbf{3 f}-\mathbf{3} \mathbf{j}$ were then used as catalysts (Table 1 , entries $\mathbf{5}-10$ ). Among them, $3 \mathbf{f}$ has the best enantioselective control ability ( $68 \%$ ee) (Table 1, entry 6). A comparison of the results gave by catalysts $\mathbf{3 d}$ and $\mathbf{3 f}$ showed that the methoxy group of $\mathbf{3 f}$ benefited the enantioselectivity of $\mathbf{4 a}$ significantly; therefore, modified catalysts $\mathbf{3 k}$ and $\mathbf{3} \mathbf{l}$ were synthesized and used in this reaction.

a) Donors used in the previous study

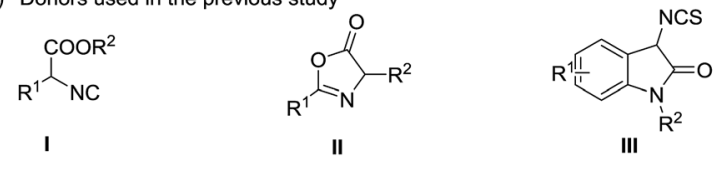

b) This study

$$
\begin{aligned}
& \text { isothiocyanatos }{ }_{\text {azodicarboxylates }} \\
& \mathrm{Pg}=\mathrm{N}\left(\mathrm{COOR}^{2}\right) \mathrm{NHCOOR}^{2}
\end{aligned}
$$

Scheme 1 Strategy for the synthesis of polysubstituted chiral 1,2,4triazolines. 
Table 1 Screening catalysts

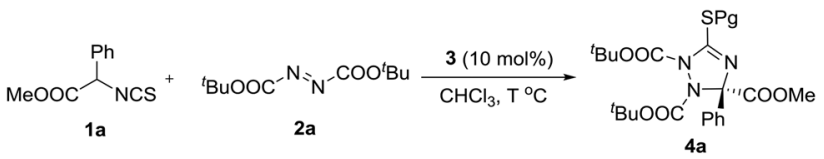

$$
\begin{aligned}
& \mathrm{Pg}=\mathrm{N}\left(\mathrm{COO}^{t} \mathrm{Bu}\right) \mathrm{NHCOO}^{t} \mathrm{Bu}
\end{aligned}
$$

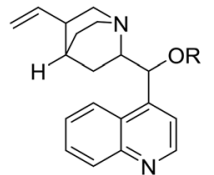

3a: cinconine

3b: $R=B n$

3c: $R=B s$

3d: $R=B z$
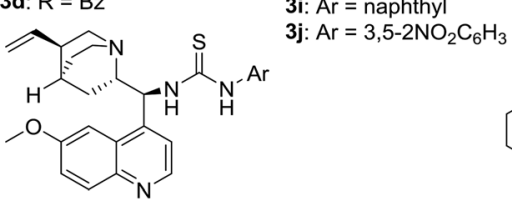

3m: $\mathrm{Ar}=\mathrm{Ph}$

3n: $\mathrm{Ar}=3,5-2 \mathrm{CF}_{3} \mathrm{C}_{6} \mathrm{H}_{3}$

3o: $\mathrm{Ar}=4-\mathrm{CH}_{3} \mathrm{C}_{6} \mathrm{H}_{4}$

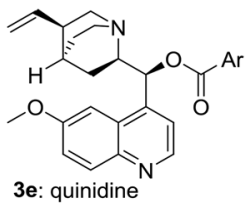

3e: quinidine

3f: $\mathrm{Ar}=\mathrm{Ph}$

3g: $\mathrm{Ar}=4-\mathrm{FC}_{6} \mathrm{H}_{4}$

3h: $\mathrm{Ar}=4-\mathrm{NO}_{2} \mathrm{C}_{6} \mathrm{H}_{4}$

$3 \mathrm{j}: \mathrm{Ar}=3,5-2 \mathrm{NO}_{2} \mathrm{C}_{6} \mathrm{H}_{3}$

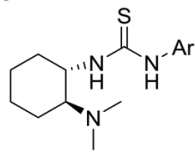

$3 p: A r=P h$

3q: $\mathrm{Ar}=4-\mathrm{MeC}_{6} \mathrm{H}_{4}$

$3 \mathrm{r}: \mathrm{Ar}=4-\mathrm{NO}_{2} \mathrm{C}_{6} \mathrm{H}_{4}$

\begin{tabular}{|c|c|c|c|c|c|}
\hline Entry & 3 & $T\left({ }^{\circ} \mathrm{C}\right)$ & Time (h) & Yield $^{a}(\%)$ & $\mathrm{ee}^{b}(\%)$ \\
\hline 1 & $3 a$ & 10 & 16 & 96 & 19 \\
\hline 2 & $3 \mathbf{b}$ & 10 & 120 & 10 & $<5$ \\
\hline 3 & $3 c$ & 20 & 96 & 11 & $<5$ \\
\hline 4 & $3 d$ & 10 & 144 & 25 & -40 \\
\hline 5 & $3 e$ & 10 & 21 & 64 & $<5$ \\
\hline 6 & $3 f$ & 20 & 92 & 22 & -68 \\
\hline 7 & $3 g$ & 20 & 36 & 14 & -62 \\
\hline 8 & $3 h$ & 20 & 76 & 9 & -58 \\
\hline 9 & $3 \mathbf{i}$ & 20 & 53 & 16 & 46 \\
\hline 10 & $3 \mathbf{j}$ & 20 & 70 & 29 & $<-5$ \\
\hline 11 & $3 \mathbf{k}$ & 20 & 104 & 19 & 58 \\
\hline 12 & 31 & 20 & 104 & 14 & 69 \\
\hline 13 & $3 \mathrm{~m}$ & 10 & 66 & 29 & $<5$ \\
\hline 14 & $3 n$ & 10 & 66 & 29 & $<5$ \\
\hline 15 & 30 & 10 & 53 & 29 & $<5$ \\
\hline 16 & $3 p$ & 10 & 120 & 20 & 29 \\
\hline 17 & $3 q$ & 10 & 65 & 10 & 19 \\
\hline 18 & $3 r$ & 20 & 144 & 20 & $<5$ \\
\hline
\end{tabular}

${ }^{a}$ Isolated yield. ${ }^{b}$ Determined by chiral HPLC.

However, no better result was obtained (Table 1, entries 11 and 12). Bifunctional catalysts $\mathbf{3} \mathbf{m}-\mathbf{3 r}$ have been extensively used as chiral organocatalysts, but they were not suitable promoters for this transformation (Table 1, entries 13-18). Therefore, catalyst 3f was selected as the optimal catalyst for further investigating the reaction conditions.

With the optimal catalyst in hand, other reaction conditions were investigated for further improving the yield and enantioselectivity. First, solvents were screened. As shown in Table 2, $m$ xylene was the best solvent for this transformation. Not only the yield increased to $70 \%$, but the enantioselectivity excess was enhanced to $78 \%$ (Table 2, entry 7 ). Then, this reaction was carried out at a low temperature $\left(-20^{\circ} \mathrm{C}\right)$. The enantioselectivity
Table 2 Further optimization of reaction conditions

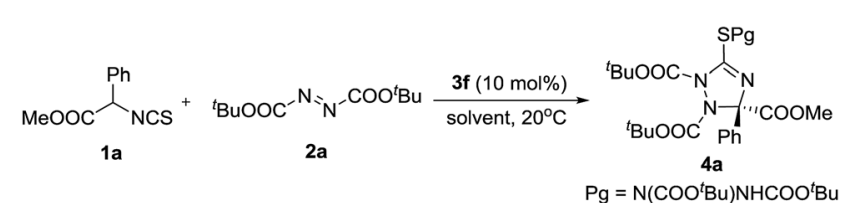

\begin{tabular}{lllll}
\hline Entry & Solvent & Time $(\mathrm{h})$ & Yield $^{a}(\%)$ & ee $^{b}(\%)$ \\
\hline 1 & $\mathrm{Et}_{2} \mathrm{O}$ & 89 & 11 & 71 \\
2 & $\mathrm{MTBE}$ & 89 & 21 & 65 \\
3 & ${ }^{n} \mathrm{Bu}_{2} \mathrm{O}$ & 71 & 52 & 75 \\
4 & $\mathrm{DCM}$ & 73 & 55 & 49 \\
5 & $\mathrm{CHCl}_{3}$ & 92 & 22 & 68 \\
6 & Toluene & 73 & 48 & 78 \\
7 & $m$-Xylene & 64 & 56 & 78 \\
8 & $m$-Xylene & 70 & 57 & $86^{c}$ \\
9 & $m$-Xylene & 96 & 77 & $89^{c, d}$
\end{tabular}

${ }^{a}$ Isolated yield. ${ }^{b}$ Determined by chiral HPLC. ${ }^{c}$ At $-20{ }^{\circ}$ C. ${ }^{d} 20 \mathrm{mg}$ $\mathrm{Na}_{2} \mathrm{SO}_{4}$ was added.

was further improved to $86 \%$ ee (Table 2, entry 8). Additives also affected the reaction outcomes. The yield and enantioselectivity of $4 \mathbf{a}$ increased to $77 \%$ and $89 \%$ ee when $\mathrm{Na}_{2} \mathrm{SO}_{4}$ was added to the reaction (Table 2, entry 9).

The substrate scope of the reaction was investigated under the optimal reaction conditions. First, the substituent effects of isothiocyanato esters $\mathbf{1}$ were studied. The results are shown in Table 3. Electron-withdrawing group substituted isothiocyanates were good reaction partners in this reaction, leading to the chiral 1,2,4-triazolines $\mathbf{4 b} \mathbf{b}-\mathbf{e}$ in good yields and enantioselectivities (Table 3, entries 2-5). The low yield of product $\mathbf{4 f}(15 \%)$ was partially caused by the steric influence of the $o$-substituent (Table 3, entry 6). We found the electrondonating groups of compounds $\mathbf{1}$ could give the products $\mathbf{4 h}$ $4 \mathbf{j}$ in high enantioselectivities, albeit the yield decreased slightly (Table 3, entries 8-10). The 2,5-dimethyl-phenyl-substituted isothiocyanate did not participate in this reaction (Table 3 , entry 11). This was probably caused by the steric effect of the bulky $o$-methyl group. The alkyl groups of compounds $\mathbf{2}$ and $\mathbf{1}$ were then investigated. We found the yields increased greatly when the tert-butyl group of 2 was replaced by iso-propyl and ethyl groups, albeit the enantioselectivities decreased (Table 3, entries 12 and 13). These results indicated this transformation would be speeded if an azodicarboxylate bearing small alkyl group was introduced as acceptor. So, compounds 1 having $o$ substituted phenyls, which could not react with di-tert-butyl azodicarboxylate efficiently (Table 3, entries 6 and 11), were used as donors to react with di-iso-propyl and ethyl azodicarboxylates, respectively (Table 3, entries 17-20). As expected, these reactions took place smoothly, giving the products in moderate to good yields and high to excellent enantioselectivities. Particularly, the highest enantioselectivity ( $95 \%$ ee) in this work was obtained in the reaction of 2-Cl phenyl substituted isothiocyanate with diisopropyl azodicarboxylate (Table 3, entry 17). The damage of enantioselectivities of products $\mathbf{4 l}$ and $\mathbf{4 m}$ 
Table 3 Substrate scope

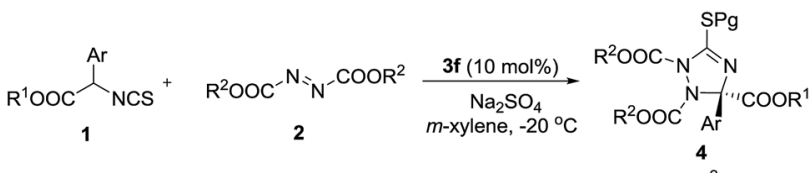

$$
\begin{aligned}
& \mathrm{Pg}=\mathrm{N}\left(\mathrm{COOR}^{2}\right) \mathrm{NHCOOR}^{2}
\end{aligned}
$$

\begin{tabular}{|c|c|c|c|c|c|c|c|}
\hline Entry & 4 & $\mathrm{Ar}$ & $\mathrm{R}^{1}$ & $\mathrm{R}^{2}$ & Time (h) & Yield $^{a}(\%)$ & $\mathrm{ee}^{b}(\%)$ \\
\hline 1 & $4 a$ & $\mathrm{Ph}$ & $\mathrm{Me}$ & ${ }^{t} \mathrm{Bu}$ & 96 & 77 & 89 \\
\hline 2 & $4 b$ & $4-\mathrm{ClC}_{6} \mathrm{H}_{4}$ & $\mathrm{Me}$ & ${ }^{t} \mathrm{Bu}$ & 91 & 75 & 88 \\
\hline 3 & $4 c$ & $4-\mathrm{FC}_{6} \mathrm{H}_{4}$ & $\mathrm{Me}$ & ${ }^{t} \mathrm{Bu}$ & 120 & 68 & 88 \\
\hline 4 & $4 d$ & $4-\mathrm{CF}_{3} \mathrm{C}_{6} \mathrm{H}_{4}$ & $\mathrm{Me}$ & ${ }^{t} \mathrm{Bu}$ & 64 & 65 & 82 \\
\hline 5 & $4 e$ & $3-\mathrm{CF}_{3} \mathrm{C}_{6} \mathrm{H}_{4}$ & $\mathrm{Me}$ & ${ }^{t} \mathrm{Bu}$ & 70 & 70 & 71 \\
\hline 6 & 4f & $2-\mathrm{ClC}_{6} \mathrm{H}_{4}$ & $\mathrm{Me}$ & ${ }^{t} \mathrm{Bu}$ & 120 & 15 & $\mathrm{Nd}^{c}$ \\
\hline 7 & $4 g$ & $4-\mathrm{F}-3-\mathrm{MeC}_{6} \mathrm{H}_{3}$ & $\mathrm{Me}$ & ${ }^{t} \mathrm{Bu}$ & 88 & 70 & 85 \\
\hline 8 & $4 \mathrm{~h}$ & $4-\mathrm{MeOC}_{6} \mathrm{H}_{4}$ & $\mathrm{Me}$ & ${ }^{t} \mathrm{Bu}$ & 120 & 54 & $85^{d}$ \\
\hline 9 & $4 \mathbf{i}$ & 4 -VillylOC ${ }_{6} \mathrm{H}_{4}$ & $\mathrm{Me}$ & ${ }^{t} \mathrm{Bu}$ & 120 & 53 & $84^{d}$ \\
\hline 10 & $4 j$ & $4-\mathrm{BnOC}_{6} \mathrm{H}_{4}$ & $\mathrm{Me}$ & ${ }^{t} \mathrm{Bu}$ & 120 & 56 & $84^{d}$ \\
\hline 11 & $4 \mathbf{k}$ & $2,5-2 \mathrm{MeC}_{6} \mathrm{H}_{3}$ & $\mathrm{Me}$ & ${ }^{t} \mathrm{Bu}$ & 24 & Trace & $\mathrm{Nd}$ \\
\hline 12 & 41 & $\mathrm{Ph}$ & $\mathrm{Me}$ & ${ }^{\mathrm{i}} \mathrm{Pr}$ & 79 & 72 & 38 \\
\hline 13 & $4 \mathrm{~m}$ & $\mathrm{Ph}$ & $\mathrm{Me}$ & Et & 26 & 76 & 14 \\
\hline 14 & $4 n$ & $\mathrm{Ph}$ & Et & ${ }^{\mathrm{i}} \mathrm{Pr}$ & 24 & 49 & 49 \\
\hline 15 & 40 & $\mathrm{Ph}$ & ${ }^{\mathrm{i}} \mathrm{Pr}$ & Et & 57 & 78 & 62 \\
\hline 16 & $4 p$ & $\mathrm{Ph}$ & ${ }^{\mathrm{i}} \mathrm{Pr}$ & ${ }^{\mathrm{i}} \mathrm{Pr}$ & 108 & 51 & 76 \\
\hline 17 & $4 q$ & $2-\mathrm{ClC}_{6} \mathrm{H}_{4}$ & $\mathrm{Me}$ & ${ }^{\mathrm{i}} \operatorname{Pr}$ & 64 & 58 & 95 \\
\hline 18 & $4 \mathbf{r}$ & $2-\mathrm{ClC}_{6} \mathrm{H}_{4}$ & $\mathrm{Me}$ & Et & 94 & 87 & 83 \\
\hline 19 & $4 s$ & $2,5-2 \mathrm{MeC}_{6} \mathrm{H}_{3}$ & $\mathrm{Me}$ & ${ }^{\mathrm{i}} \mathrm{Pr}$ & 216 & 41 & $77^{e}$ \\
\hline 20 & $4 t$ & $2,5-2 \mathrm{MeC}_{6} \mathrm{H}_{3}$ & $\mathrm{Me}$ & Et & 72 & 44 & $72^{e}$ \\
\hline
\end{tabular}

${ }^{a}$ Isolated yield. ${ }^{b}$ Determined by chiral HPLC. ${ }^{c}$ Not determined. ${ }^{d}$ At $20{ }^{\circ} \mathrm{C} .{ }^{e}$ At $50{ }^{\circ} \mathrm{C}$.

could be complemented through increasing the bulk of alkyl group of isothiocyanate 1. For example, the enantioselectivities increased greatly when we used ethyl and isopropyl isothiocyanato esters as donors (Table 3, entries 14-16). The absolute configuration $(S)$ of compound $\mathbf{4 q}$ was determined by single crystal X-ray analysis (see ESI $\dagger$ ). ${ }^{\mathbf{1 0}}$ The absolute configuration of compounds $\mathbf{4}$ and $\mathbf{5}$ were assigned accordingly.

Enantioenriched compounds $\mathbf{4}$ can be readily converted into other 1,2,4-triazolines under mild reaction conditions. As described in Scheme 2, the alkylation of compound $\mathbf{4 q}$ with benzyl bromide or allylic bromide afforded novel triazolines 5a and $\mathbf{5 b}$ in good yields (Scheme 1, eqn (1) and (2)). Furthermore,

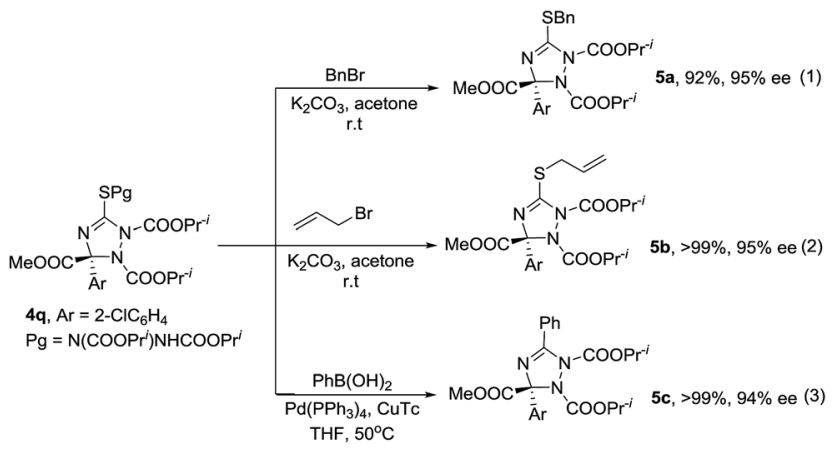

Scheme 2 Transformation of product 4q. compound $\mathbf{4 q}$ could couple with phenylboronic acid and give product 5c in a high yield (Scheme 1, eqn (3)). Importantly, the enantioselectivity of $\mathbf{4 q}$ was transformed into the corresponding products completely.

\section{Conclusion}

In conclusion, an efficient organocatalytic method was developed for the synthesis of chiral 1,2,4-triazolines, in which, the amino-acid-derived isothiocyanato esters were used as the donors for the first time. Triazoline products were obtained in good yields and good to excellent enantioselectivities, and could be converted into other compounds without the loss of enantioselectivities.

\section{Acknowledgements}

We are grateful for financial support from NSFC (21472150, 21272002), the Fundamental Research Funds for the Central Universities (XDJK2013B028) and the Program for New Century Excellent Talents in Universities (NCET-12-0929).

\section{Notes and references}

1 (a) K. T. Potts, Chem. Rev., 1961, 61, 87; (b) A. Moulin, M. Bibian, A.-L. Blayo, S. EI Habnouni, J. Martinez and J.-A. Fehrentz, Chem. Rev., 2010, 110, 1809; (c) D. Astruc, L. Liang, A. Rapakousiou and J. Ruiz, Acc. Chem. Res., 2012, 45, 630 .

2 (a) S. Maddila, R. Pagadala and S. B. Jonnalagadda, Lett. Org. Chem., 2013, 10, 693; (b) C. H. Zhou and Y. Wang, Curr. Med. Chem., 2012, 19, 239.

3 (a) L. Yet, Prog. Heterocycl. Chem., 2011, 23, 231; (b) K. Sharma and B. Lal, J. Steroid Biochem. Mol. Biol., 2007, 107, 270; (c) S. D. Barchéchath, R. I. Tawatao, M. Corr, D. A. Carson and H. B. Cottam, J. Med. Chem., 2005, 48, 6409; (d) O. G. Todoulou, A. E. Papadaki-Valiraki, S. Ikeda and E. D. Clercq, Eur. J. Med. Chem., 1994, 29, 611.

4 Selected examples see: $(a)$ T. Kolasa and M. Miller, Tetrahedron Lett., 1988, 29, 4661; (b) T. Ibata, Y. Isogami and H. Tamura, Chem. Lett., 1988, 1551; (c) A. Hassner and B. Fischer, Tetrahedron, 1989, 45, 3535; (d) D. J. Anderson and W. Watt, J. Heterocycl. Chem., 1995, 32, 1525; (e) O. Tsuge, T. Hatta, H. Tashiro and H. Maeda, Heterocycles, 2001, 55, 243; (f) R. S. Z. Saleem and J. J. Tepe, J. Org. Chem., 2010, 75, 4330.

5 (a) D. Monge, K. L. Jensen, R. Marín and K. A. Jørgensen, Org. Lett., 2011, 13, 328; (b) M. Wang, X. Liu, P. He, L. Lin and X. Feng, Chem. Commun., 2013, 49, 2572; (c) Q. Shao, J. Chen, M. Tu, D. W. Piotrowski and Y. Huang, Chem. Commun., 2013, 49, 11098; (d) M.-X. Zhao, H.-L. Bi, H. Zhou, H. Yang and M. Shi, J. Org. Chem., 2013, 78, 9377.

6 Y. Jiang, C.-K. Pei, D. Du, X.-G. Li, Y.-N. He, Q. Xu and M. Shi, Eur. J. Org. Chem., 2013, 7895.

7 Selected examples: (a) L. Li, E. G. Klauber and D. Seidel, J. Am. Chem. Soc., 2008, 130, 12248; (b) M. C. Willis, G. A. Cutting, V. J.-D. Piccio, M. J. Durbin and M. P. John, 
Angew. Chem., Int. Ed., 2005, 44, 1543; (c) X. Chen, Y. Zhu, Z. Qiao, M. Xie, L. Lin, X. Liu and X. Feng, Chem.-Eur. J., 2010, 16, 10124; (d) W.-Y. Han, J.-Q. Zhao, Z.-J. Wu, X.-M. Zhang and W.-C. Yuan, J. Org. Chem., 2013, 78, 10541; (e) Y.-M. Cao, F.-F. Shen, F.-T. Zhang, J.-L. Zhang and R. Wang, Angew. Chem., Int. Ed., 2014, 53, 1862; $(f)$ W.-B. Chen, W.-Y. Han, Y.-Y. Han, X.-M. Zhang and W.-C. Yuan, Tetrahedron, 2013, 69, 5281.

8 Selected examples: (a) X. Jiang, Y. Cao, Y. Wang, L. Liu, F. Shen and R. Wang, J. Am. Chem. Soc., 2010, 132, 15328; (b) W.-B. Chen, Z.-J. Wu, J. Hu, L.-F. Cun, X.-M. Zhang and W.-C. Yuan, Org. Lett., 2011, 13, 2472; (c) T. Yoshino, H. Morinoto, G. Lu, S. Matsunaga and M. Shibasaki, J. Am. Chem. Soc., 2009, 131, 17082; (d) M. K. Vecchione and
D. Seidel, Chem. Commun., 2010, 46, 4604; (e) X. Jiang, G. Zhang, D. Fu, Y. Cao, F. Shen and R. Wang, Org. Lett., 2010, 12, 1544.

9 Selected examples: (a) L. Li, M. Ganesh and D. Seidel, J. Am. Chem. Soc., 2009, 131, 11648; (b) Z. Shi, P. Yu, P. J. Chua and G. Zhong, Adv. Synth. Catal., 2009, 351, 2797; (c) G. A. Cutting, M. E. Stainforth, M. P. John, C. Kociok-Kohn and M. C. Willis, J. Am. Chem. Soc., 2007, 129, 10632; (d) X. Chen, S. Dong, Z. Qiao, M. Xie, L. Lin, X. Liu and X. Feng, Chem.-Eur. J., 2011, 17, 2583; (e) S. Kato, T. Yoshino, M. Shibasaki, M. Kanai and S. Matsunaga, Angew. Chem., Int. Ed., 2012, 51, 7007.

10 CCDC 1043418 (4q) contains the supplementary crystallographic data for this paper. $\dagger$ 